\title{
The Interrelation of Semantic Structure and Syntactic Variation in Old English Verb Classes: Catalogue of Syntactico-Semantic Constructions ${ }^{1}$
}

\section{Marta González Orta \\ UNED}

maorta@bec.uned.es

\begin{abstract}
The aim of this paper is to motivate the syntactic and morphological behaviour of the Old English verbs which share the core meaning of 'to remember', 'to emit a smell', 'to produce a sound' and 'to speak' from their semantic structure. Firstly, as a result of the analysis of these verb subclasses, I will propose a subclass-based lexical template for each lexical subclass. Within the Lexical Grammar Model, lexical templates are conceived as lexical representations where meaning description is encapsulated and interacts with the syntactic behaviour of lexical units. In order to construct a lexical template, Role and Reference Grammar logical structures will be complemented by a semantic decomposition which will define different lexical (sub-)classes.

Secondly, the Lexical Template Modelling Process will stipulate the linking between the syntactic and semantic representation of these verbs. This process will establish the lexical rules that account for the mapping between the different semantic constructions and the syntactic structures and alternations in which these verbs participate and the lexical templates codified by these verb subclasses. As a result, a catalogue of the syntactico-semantic constructions exhibited by these Old English verbal predicates will be provided.
\end{abstract}

\section{Introduction}

The aim of this paper is to describe the interaction of meaning and syntax in the Old English set of remember, smell emission, sound emission and speak verbs. As Mairal and Cortés 
(forthcoming) state, "one of the most interesting challenges for linguistic models in the last years is the design of a syntax-semantics interface whose central task should be to link lexical representations with morphological and syntactic structures, ideally in a bidirectional fashion".

This, in fact, is the major concern of the Lexical Grammar Model (henceforth LGM). This theoretical framework puts forward a procedure of lexical representation by means of an inventory of lexical templates which encode the semantic description of a lexical (sub-)class in a formal system of representation, together with a set of lexical mapping rules which will enable us to account for the syntactic and morphological configuration of a given predicate.

This proposal is based on the following basic claims about lexical organization (Mairal and Cortés, forthcoming):

(a) the lexicon should be organized into coherent semantic (sub-)classes;

(b)lexical (sub-)classes are receptacles of a rich set of linguistic regularities, as the predicates of a lexical (sub-)class share both a semantic and a syntactic territory;

(c) from (b) follows that the lexicon is a source of syntactic predictability.

Therefore, the lexicon in the LGM not only codifies how lexemes are arranged in a hierarchy of lexical (sub-)classes, but is also a determining factor in their syntactic behaviour. As Faber and Mairal (1999: 143) state:

In the (...) lexicon, paradigmatic and syntagmatic information are closely interrelated to the extent that a verb's syntax depends on its location on the semantic space. In other words, a verb's combinatorial possibilities and syntactic potential are semantically motivated.

The structure of this paper will be as follows: firstly, we will explain the procedure for selecting the corpus of Old English predicates that belong to the lexical subclasses of remember, smell emission, sound emission and speak verbs; secondly, we will concentrate on the concept of lexical template, together with the linking algorithm which will model the lexical template corresponding to a given subclass in order to account for the morphosyntactic structures shown by the predicates which conform it; thirdly, we will construct the lexical templates that constitute the semantic representation of the verbal predicates mentioned above, as the input for providing the catalogue of syntactico-semantic constructions exhibited by the members of these four verb subclasses.

\section{Corpus selection}

Following the assumption that lexical (sub-)classes remain diachronically constant for the most part (Cortés and Torres, 2003), the Old English subclasses under study will be constructed turning the information from the Thesaurus of Old English (TOE) into the 
structure of these subclasses in Present-day English (Faber and Mairal, 1999: 286-288, 290). Then, the information extracted from the TOE will be checked against the definitions contained in the Old English lexicographical sources by Bosworth \& Toller (B\&T), Toller \& Campbell (T\&C) and Hall.

In this regard, we have primarily selected four verb classes from the Old English lexicon, that is, cognition, perception, sound and speech, and within them the lexical subclasses corresponding to remember, smell emission, sound emission and speak verbs, respectively. We postulate that the syntactico-semantic constructions codified by these subclasses can be highly representative of the constructions exhibited by the verbal predicates in the first phase of the English language.

Taking into account their core meaning, we will be able to group the verbal predicates provided by the TOE as follows:

(a) To think about something bringing it back into one's mind from the past [remember verbs]: eftgemynd(i)gian, (ge)healdan, gemunan, (ge)mynegian, gepencan, hycgan, mimorian, ofmunan, ofpencan (TOE: 06.01.04)

(b) To emit a smell [smell verbs]: apmian, besmocian, bladesian, epian, (ge)stincan, geswceccan, gewyrtian, hrenian, recelsian, reocan, steran, tostincan (TOE: 02.05.08)

(c) To make a loud sound [shout verbs]: breodian, bylgan, ceallian, (ge)ciegan, circian, cirman, (ge)clipian, gegan, gradan, grimman, hlydan, hrepan, hrieman, ofclipian, oferclipian, scraman, styrman (TOE: 02.05.10.15.01)

(d) To say something [speak verbs]: (ge)cwepan, (ge)cypan, (ge)secgan, (ge)sprecan (TOE: 09.01)

As stated above, the lexemes belonging to a given verb subclass will show basically the same morphological and syntactic behaviour, except for certain particularities which may arise in a detailed description of these lexical units. As Cortés and Mairal (2002: 15-16) state, "by combining the information from different lexicographical sources [..] the level of differentiae specificae [...] seems impossible to determine: a definitive ascertainment of sense-relations among lexemes is implausible unless further sources of information are used". Therefore, the next step will be to obtain and analyse the contexts in which these lexemes appear by locating the lexemes that integrate these four subclasses in B\&T, T\&C, The Helsinki Corpus of English Texts (HSK) and The Dictionary of Old English Corpus (DOEC).

\section{The concept of lexical template: Semantic decompositions enrich Role and Reference Grammar logical structures}

In this section, we will provide a brief account of the notion of lexical template. Within the LGM, lexical templates are conceived as lexical representations which include 
syntactic and semantic information within the same format, supplying Role and Reference Grammar logical structures (RRG's LSs) with a semantic decomposition which will define different lexical classes. This has been pointed out by several authors (Cortés and Torres, 2003; Mairal and Cortés, forthcoming; Mairal and Faber, 2002; Van Valin, 2004).

Van Valin and LaPolla (1997) propose a system of lexical representation, by means of LSs which describe verbal predicates in terms of their Aktionsart or internal temporal properties. This classification implies a way to capture syntactic and morphological phenomena, such as the combinatory possibilities of predicates and case assignment, characteristic of the different verb classes. Thus, within RRG six verb classes are distinguished, that is, states [ + static, -telic, -punctual], activities [-static, -telic, punctual], achievements [-static, +telic, +punctual], semelfactives [ \pm static], [-telic ], [ + punctual ], accomplishments and active accomplishments [-static, +telic, punctual], together with their causative counterparts (Van Valin, 2004):

Verb Class Logical Structure

STATE

ACTIVITY

ACHIEVEMENT

SEMELFACTIVE

ACCOMPLISHMENT

ACTIVE ACCOMPLISHMENT

predicate' $(\mathrm{x})$ or $(\mathrm{x}, \mathrm{y})$

do $^{\prime}(\mathrm{x}$, [predicate' $(\mathrm{x})$ or $(\mathrm{x}, \mathrm{y})]$ )

INGR predicate' $(\mathrm{x})$ or $(\mathrm{x}, \mathrm{y})$, or

INGR do' ( $\mathrm{x}$, [predicate' $(\mathrm{x})$ or $(\mathrm{x}, \mathrm{y})$ ])

SEML predicate' $(\mathrm{x})$ or $(\mathrm{x}, \mathrm{y})$

SEML do' ( $\mathrm{x}$, [predicate' $(\mathrm{x})$ or $(\mathrm{x}, \mathrm{y})]$ )

ACCOMPLISHMENT BECOME predicate ${ }^{\prime}(\mathrm{x})$ or $(\mathrm{x}, \mathrm{y})$, or

BECOME do' $\left(x\right.$, predicate $^{\prime}(\mathrm{x})$ or $\left.(\mathrm{x}, \mathrm{y})\right]$ )

CAUSATIVE

$(\mathrm{x},(\mathrm{y}))$ ]) \& INGR predicate2' $(\mathrm{z}, \mathrm{x})$ or $(\mathrm{y})$

$\alpha$ ? CAUSE $\beta$, where $\alpha, \beta$ ?are LSs of any type

Table 1. Lexical representations for Aktionsart classes

By way of illustration, the following examples extracted from Van Valin (2004):

\section{a. STATES}

Dana saw the picture. see' (Dana, picture)

b. ACTIVITIES

Carl ate pizza. do' (Carl, [eat' (Carl, pizza)])

c. ACHIEVEMENTS

The window shattered. INGR shattered' (window)

d. SEMELFACTIVES

Dana glimpsed the picture. SEML see' (Dana, picture)

e. ACCOMPLISHMENTS

The snow melted. BECOME melted' (snow) 


\section{f. ACTIVE ACCOMPLISHMENTS}

Carl ate the pizza. do' (Carl, [eat' (Carl, pizza)]) \& INGR consumed' (pizza)

g. CAUSATIVES

STATE: The dog scared the boy. [do' $(\operatorname{dog}, \varnothing)]$ CAUSE [feel' (boy, [afraid'])] ACTIVITY: Felix bounced the ball. [do' (Felix, Ø)] CAUSE [do' (ball, [bounce' (ball)])]

ACHIEVEMENT: The burglar shattered the window. [do' (burglar, Ø)] CAUSE

[INGR shattered" (window)]

SEMELFACTIVE: Sam flashed the light. [do' (Sam, Ø)] CAUSE [SEML do' (light, [flash' (light)])]

ACCOMPLISHMENT: Max melted the ice. [do' (Max, Ø)] CAUSE [BECOME melted' (ice)]

ACTIVE ACCOMPLISHMENT: [do' (Mary, Ø)] CAUSE [do' (child, [eat' (child, pizza)]) \& INGR consumed' (pizza)]

As table 1 shows, LSs follow the conventions of formal semantics. Constants, in boldface followed by a prime, are part of the semantic metalanguage and will be applied to any language. However, variables in normal typeface are filled by lexical items from the language under study. Finally, the elements in capitals, such as INGR, SEML, BECOME, or CAUSE, will modify the predicate (Van Valin and LaPolla, 1997: 102).

In order to attain the argument structure of a verb, Van Valin and LaPolla (1997: 139) propose two general semantic relations, the Actor and Undergoer macroroles, which are "generalizations across the argument-types found with particular verbs which have significant grammatical consequences." As the Actor-Undergoer Hierarchy below shows (Valin and LaPolla, 1997: 146), the Actor macrorole comprises those arguments whose nature is closer to that of an Agent and the Undergoer subsumes those arguments closer to a Patient:

ACTOR

UNDERGOER

\begin{tabular}{|c|c|c|c|c|}
\hline $\begin{array}{l}\text { Arg. of } \\
\text { DO }\end{array}$ & $\begin{array}{l}1^{\text {st }} \text { arg. of } \\
\text { do' }(x, \ldots\end{array}$ & $\begin{array}{l}1^{8 t} \arg \text { of } \\
\text { pred }^{\prime}(x, y)\end{array}$ & $\begin{array}{l}2^{\text {nd }} \text { arg. of } \\
\text { pred }^{\prime}(x, y)\end{array}$ & $\begin{array}{l}\text { Arg. of state } \\
\text { pred }^{\prime}(x)\end{array}$ \\
\hline
\end{tabular}

$\left[{ }^{\prime} \rightarrow{ }^{\prime}=\right.$ increasing markedness of realization of argument as macrorole]

Figure 1. Actor-Undergoer Hierarchy.

Kailuweit (2004) points out the fact that macroroles are categories mediating between semantics and syntax. Consequently, they also have morphosyntactic characteristics: in Old English macroroles are assigned to core arguments, that is, arguments marked by a grammatical case (Allen, 1995; Denison, 1993; Fischer et al., 2000; McLaughlin, 1983; Mitchell, 1985), in opposition to oblique arguments, which are introduced by 
prepositions.

The interaction between arguments and macroroles is established in the macrorole assignment principles (Van Valin and LaPolla, 1997: 152-53):

Number: the number of macroroles a verb takes is less than or equal to the number of arguments in its LS,

If a verb has two or more arguments in its LS, it will take two macroroles.

If a verb has one argument in its LS, it will take one macrorole.

Nature: for verbs which take one macrorole,

If the verb has an activity predicate in its LS, the macrorole is actor.

If the verb has no activity predicate in its LS, the macrorole is undergoer.

Moreover, case assignment rules are also related to the assignment of macroroles. Based on Van Valin and LaPolla (1997: 359), we propose the following case assignment rules for Old English verbs:

Assign nominative case to the highest-ranking macrorole argument, that is, the Actor. Assign accusative case to the other macrorole argument, that is, the Undergoer.

Assign dative or genitive to non-macrorole arguments. ${ }^{2}$

One important feature of the LGM is the assumption that taking into account the interaction existing between macroroles and grammatical relations, the information to be included in the lexical representations will be greatly reduced. However, a detailed description of lexical units is necessary, since LSs lack the semantic information characteristic of lexical classes. This is achieved by incorporating the semantic features (semantic primitives and internal variables) and the syntactic features (external variables) common to the set of verbs which belong to the same lexical class into a unified representation. Accordingly, Mairal and Faber (2002: 54) describe lexical templates in the following terms:

Lexical templates conflate both syntactic information (those aspects of the meaning of a word which are grammatically relevant) and semantic information (those aspects which act as distinctive parameters within a whole lexical class) into one unified representation.

\section{The linking algorithm within the LGM}

Lexical templates not only will include the semantic information corresponding to the set of verbs which belong to the same verb (sub-)class, but will also allow us to explain the morpho-syntactic structures and alternations shown by these verbal predicates. Therefore, the linking system entails two phases: the first phase of linking will depart from the lexical template in order to provide an adequate description of the semantics of the constructions 
in which the different sets of verbs participate; on the other hand, the second phase of linking will make use of a set of morpho-syntactic rules in order to describe the morphological and syntactic structure of the constituents in the different constructions.

The first phase of the linking algorithm attempts to apply the Lexical Template Modelling Process which, by means of an inventory of lexical mapping rules proposed by Mairal and Cortés (forthcoming), will enable us to account for the mapping between the lexical templates and the semantic constructions with their corresponding constructionbased templates shown by the members of lexical (sub-)classes. The Lexical Template Modelling Process has been summarised by Mairal and Faber (2002: 87) as follows:

Lexical templates can be modeled by suppressing external variables, instantiating internal variables, eliminating operators (e.g. CAUSE), or else, by introducing elements resulting from the fusion with other templates iff there is a compatibility between the features in the lexical template and the syntactic construction under scrutiny.

Taking into account the previous discussion, the constructions to be presented below will support the view within the LGM "when it is postulated that, prior to the assignment of morpho-syntactic rules, there is a linking phase between the lexical templates of a class and the constructions where the predicates of such a class participate. (...). Constructional templates are (...) considered independent entities in the model with a capacity to contribute to the final semantic configuration of sentences" (Cortés and González, 2004). With regard to the second phase of linking, the macrorole assignment principles and case assignment rules will predict the syntactic and morphological behaviour of Old English verbal predicates from their semantic structure.

\section{In search of subclass-based lexical templates}

Let us introduce the lexical templates that constitute the syntactico-semantic representation of the verb subclasses under study:

\subsection{Remember verbs}

According to Van Valin and Wilkins (1993: 509), in remembering "a person starts to actively think about something, and for the duration of this activity there is an entailment that the person has this something in mind". In this regard, we will propose the following lexical template for the subclass of remember verbs in Old English:

[BECOME think.again.about.something.(á).be.in.mind.from.before' $(x, z)]$, where $\mathrm{z}=\mathrm{a}$

As expressed by the operator BECOME, this lexical representation contains the LS 
of an accomplishment codifying a change which requires duration. It shows two external variables $(x)$ and $(z)$, or external argument positions, marked in Roman letters, which will have a syntactic representation. In addition, the internal variable (á), marked in Greek and considered an ontological constant that does not necessarily receive linguistic expression, encodes the content of the predicate think' and will be linked to $(\mathrm{z})$ :

(1) Ic (x) God (z) gemyndgade (B\&T)

I-God-remembered.

\subsection{Smell emission verbs}

The corresponding lexical representation codifies mainly the emission of a smell (pleasant or unpleasant), by means of a physical or chemical process, with no specification of the source of such smell or of any causing entity or activity. Accordingly, this template denotes a stative LS headed by the predicate have' and showing an external variable (z), which corresponds to the emitter of the (un)pleasant smell (González, forthcoming):

\section{[have.smell', [be' (smell, [(un)pleasant'])] (z)]}

(2) nu he (z) stingd (HSK: Cowsgosp < R 11.39>)

Now-he-smells unpleasantly.

\subsection{Sound emission verbs}

Unlike the two previous subclass-based lexical templates, it is interesting to observe that the lexical representation corresponding to sound emission verbs involves two subevents where an effector (w) uses an instrument, codified in terms of the use' predicate and the external variable (v/voice), which in turns causes the production of a sound:

\begin{tabular}{c}
\hline$\left[\right.$ do' $^{\prime}(\mathrm{w}$, [use' (w, v/voice)] CAUSE [produce' (w, sound').in.loud.manner.(ä)' \\
(w, sound)]]
\end{tabular}

This template, thus, contains a causative activity showing three external argument positions ( $w$ ), (v/voice) and (sound) which will have a syntactic representation. Besides, the internal variable $(\delta)$, which encodes the manner in which the sound is produced, has been incorporated in this lexical representation as a semantic component denoting a loud sound (Cortés and González, 2004):

(3) Herewopa (sound) mast aðe cyrmdon (w: elliptical) (B\&T)

Cries of an army-most-hateful-cried out (they). 


\subsection{Speak verbs}

In much the same vein, the template codified by speak verbs also involves two subevents where an effector $(w)$ uses an instrument (voice/words), such that this effector expresses a content (á) to an addressee $(\beta)$ in a language $(\gamma)$ :

[[do' (w, [use' (w, voice/words)] CAUSE [do' (w, [express.(á).to. $(\beta)$.in.language. $\left.\left.\left.(\gamma)^{\prime}(w, y)\right]\right)\right]$, where $y=\beta$

This template involves a causative activity showing three external argument positions (w), (voice/words) and (y), which will have a syntactic representation, together with three internal variables $(\alpha),(\beta)$ and $(\gamma)$, where (w) makes reference to the speaker and $(y)$ to $(\beta)$ or the hearer (González, 2004: 15). As a way of illustration, we present the following example:

(4) ac we (w) wyllað eow (y) secgan (DOEC: FHom 19 B1.4.19)

But-we-will-you-talk.

\section{Catalogue of syntactico-semantic verbal constructions}

Once we have described the subclass-based lexical templates codified by the Old English verbs under study, we will proceed to construct the catalogue of syntactico-semantic constructions shown by these predicates by means of construction-based templates.

As Van Valin and Wilkins (1993: 499) state, "the types and form of the complements that a predicate takes can be deduced directly from the semantic representation in its lexical entry. (...) the syntactic properties of its complements will be derived from that representation together with a set of independently-motivated, language-specific and universal semantic, lexical and morphosyntactic principles". Therefore, applying the Lexical Template Modelling Process to the lexical templates presented above, we will obtain the full range of construction-based templates corresponding to the semantic constructions in which these verbal predicates participate.

\subsection{Transitive construction}

The first construction under analysis is the transitive construction. In RRG, transitivity becomes a semantic notion since the number of semantic macroroles a predicate takes determines it: those verbs that take two macroroles are transitive verbs, whereas those with one macrorole are intransitive; verbs which do not take any macrorole are considered atransitive.

As the Lexical Template Modelling Process stipulates, the corresponding constructionbased template below which provides a semantic representation of this construction and the lexical template codified by this subclass meet the lexical mapping rule "full matching", 
according to which there exists an identification of variables, subevents and operators between both the subclass-based template and this constructional template:

[BECOME think.again.about.something.( $\omega)$.be.in.mind.from.before' $(x, z)$, where $\omega=\mathrm{z}$

As stated above, this lexical representation contains the LS of an accomplishment showing two external argument positions (x) and (z), and an internal variable $(\omega)$, encoding the content of the predicate think', which will be linked to (z). The linking between internal and external variables will determine the syntactic behaviour of verbal lexemes. Therefore, applying RRG's macrorole and case assignment principles, the variable $(\mathrm{x})$ takes macrorole actor and nominative case, whereas the external variable $(\mathrm{z})$ in accusative will take macrorole undergoer:

(5) Ic (x: nominative - actor) God (z: accusative - undergoer) gemyndgade (B\&T) I-God-remembered.

\subsection{Resultative construction}

As its name suggests, this construction describes the state achieved as a result of an action:

(6) Jasmine pushed the door open. (Levin, 1993: 100)

The lexical mapping rule "predicate integration condition" will account for the mechanism involved in the integration of a new subevent in the constructional templates below propitiating this result:

The constructional template may introduce a new predicate into the canonical lexical template iff the semantics of the added predicate is compatible with the semantic content of the lexical template. A case in point is the middle, the caused motion and the resultative construction. (Mairal and Cortés, forthcoming)

The new subevents to be introduced are the following: the causative activity [do' (w, [use' (w, voice/words)] CAUSE [do' (w, [express.(á).to.( $\left.\left.\left.\beta) . i n . l a n g u a g e .(\gamma)^{\prime}(w, y)\right]\right)\right]$ regarding remember verbs; the activity [do' ( $\mathrm{w}$, [use' $(\mathrm{w}, \mathrm{v})])]$ with smell emission verbs; and the accomplishment [BECOME know' $(\mathrm{y}, \mathrm{z})]$ in the case of speak verbs.

[do' (w, [use' (w, voice/words)] CAUSE [do' (w, [express.(á).to.( $\beta$ ).in.language. $(\gamma)$ $(\mathrm{w}, \mathrm{y})]$ ] ] CAUSE [BECOME think.again.about.something.(á).be.in.mind.from. before' $(y, z)]$, where $y=\beta, z=a ́$

(7) Forpon ic (w: nominative-actor) eow (y: dative) manige ealle daet (z: accusative- 
undergoer) (B\&T)

Because-I-you-remind-all-that.

$\left[\right.$ do $^{\prime}\left(\mathrm{w},\left[\right.\right.$ use $\left.\left.\left.^{\prime}(\mathrm{w}, \mathrm{v})\right]\right)\right]$ CAUSE [have.smell', [be' (smell, [pleasant $\left.\left.\left.\left.{ }^{\prime}\right]\right)\right](\mathrm{z})\right]$

(8) Ster (w: elliptical-actor) hyne (z: accusative-undergoer) mid dare wyrte (v: mid + dative) (B\&T)

Perfume (you)-him-with-the-herb.

do' (w, [use' (w, voice/words)] CAUSE [do' (w, [express.(á).to.( $\beta$ ).in.language. $(\gamma)$ $(\mathrm{w}, \mathrm{y})]$ )] CAUSE [BECOME know $\left.^{\prime}(\mathrm{y}, \mathrm{z})\right]$, where $\mathrm{y}=\beta, \mathrm{z}=\mathrm{a}$

(9) Ne mihte se dumba fader (w: nominative-actor) cypan his wife (y: dative) hu se engel his cilde naman gesette (z: accusative-undergoer) (DOEC: $\mathbb{E C H o m ~ I , ~} 25 \mathrm{~B} 1.1 .27$ ) Not-might-the-silent-father-tell-his-wife-how-the-angel-his-child-name-set.

In the first subevents of the constructional templates above the external variable (w) acts as effector initiating an action (do') by using (use') an instrument, such that this effector causes (CAUSE) the act of remembering, the emission of a pleasant smell or the knowledge of a content, respectively, as encoded in the terminal subevents.

The constructional templates concerning remember and speak verbs contain the LS of a causative accomplishment. Regarding macrorole and case assignment, (w) functions as actor and takes nominative case, the variable $(\mathrm{z})$ takes macrorole undergoer and accusative case, and finally (y), as a non-macrorole argument referring to the addressee, takes dative case. On the other hand, the constructional template corresponding to smell emission verbs involves a causative state with the variable (w) as actor in nominative, (z) as undergoer in accusative and (v) will be introduced by the preposition mid.

There is one issue that still needs commenting. The resultative construction involves the link between different lexical classes: the verb classes of speech and cognition in remember and speak verbs, and action and perception in the case of smell emission verbs. As Faber and Mairal (1999: 254) state, transition zones are lexical subclasses "which are on the boundary between two areas of conceptual meaning. Lexical units within these zones can be said to belong to two domains". An example of this overlap can be also seen in the lexical classes of sound and speech, depending on whether the sound emitted is articulated or not:

(10) a She screamed/yelled/screeched/shrieked when she saw the cockroaches in the refrigerator. [SOUND]

b. She screamed/yelled/screeched/shrieked, "Look at the cockroaches in the refrigerator!" [SPEECH] (Faber and Mairal, 1999: 254)

As becomes clear from the preceding passage, the representation of the meaning of a 
given predicate must include not only its internal but also its external structure. The internal structure comes from the syntactic and semantic parameters recurring within the subclass to which a predicate belongs. Moreover, the external structure takes into account the connections existing between this predicate and others of the lexicon, resulting in a semantic network of lexical classes.

\subsection{Reaction object construction}

In order to account for the reaction object construction, Levin (1993: 98) points out the fact that "certain intransitive verbs -particularly verbs of manner of speaking and verbs of gestures and signs- take non-subcategorized objects that express a reaction (an emotion or disposition) (...). When these verbs take such objects they take on an extended sense which might be paraphrased "express (a reaction) by V-ing," where "V" is the basic sense of the verb":

(11) Paula smiled her thanks. (Levin, 1993: 98)

This construction is found with Old English sound emission verbs:

feel.about. $\left.(\beta)^{\prime}(\mathrm{w}, \mathrm{u})\right]$ CAUSE [[do' $\left(\mathrm{w},\left[\right.\right.$ use $^{\prime}(\mathrm{w}, \mathrm{v} /$ voice $\left.)\right]$ CAUSE [produce ${ }^{\prime}(\mathrm{w}$, sound').in.a.loud.manner.(ä) $(w, \emptyset)]]$, where $u=\beta$

(12) Da hrymde heo (w: nominative-actor) to hire hiwum (u: to + dative) da he gehirde dret ic hrimde (B\& $\mathrm{T})$

Then-cried out-she-to-her-appearance-when-he-heard-that-I-cried out.

This reaction object construction allows sound verbs to be linked semantically to the lexical class of feeling, and requires to encode a subevent [feel.about. $(\beta)^{\prime}(w, u)$ ] as a causing state of affairs in the emission of a sound. Given the nature of this object, which modulates the general meaning of these verbs and contributes to their semantics by having to add a specific subevent to the template (cf. "predicate integration condition"), it will be considered in RRG terms an argument-adjunct. In this case it is expressed by a "to + dative' phrase (Cortés and González, 2004).

\subsection{Instrument subject construction}

In relation to the instrument subject construction, Old English sound emission and speak verbs allow the following alternation, as shown by the constructional templates below:

(13) a. David broke the window with a hammer.

b. The hammer broke the window. (Levin, 1993: 80)

(14) a. $\mathrm{He}$ (w: nominative-actor) hlude stefne (voice: dative) ne cirmde (B\&T) 
He-loud-voice-not-cried out.

\section{[[do' (w, [use' (w, v/voice)] CAUSE [produce' (w, sound').in.a.loud.manner.(ä)' (w, voice)]]}

b Israhela beam (v: nominative-actor) hrimdon (B\&T)

Israel-trumpets-cried out.

\section{$\left[\left[\right.\right.$ do $^{\prime}\left(\varnothing\right.$, [use $^{\prime}(\varnothing, \mathrm{v} /$ voice $\left.)\right]$ CAUSE [produce' $(\mathrm{v}$,} sound').in.a.loud.manner. $\left.\left.(\delta)^{\prime}(\varnothing, v)\right]\right]$

(15) a. Daniel (w: nominative-actor) to his drihtne (y: to + dative) gesprcec sodra worda (words: genitive) (DOEC: Dan A1.3)

Daniel-to-his-God-talked-true-words.

[do' (w, [use' (w, voice/words)] CAUSE [do' (w, [express.(á).to.( $\beta$ ).in.language. $\left.\left.\left.(\gamma)^{\prime}(w, y)\right]\right)\right]$, where $y=\beta$

b. Wordo his (words: nominative-actor) gast and lif (z: accusative-undergoer) foresceged (T\&C)

Word-his-soul-and-life-proclaims.

[do' $\left(\varnothing,\left[\right.\right.$ use $^{\prime}(\varnothing$, voice/words)] CAUSE [do' $(\varnothing$,

[express.(á).to.( $(\beta)$.in.language. $(\gamma)$.in.a.formal.manner.(ä) $\left.\left.\left.{ }^{\prime}(\varnothing, \varnothing)\right]\right)\right]$

CAUSE [BECOME aware.of' $(\varnothing, \mathrm{z})]$, where $\varnothing=\beta, z=$ á

This construction tackles with the issue of an instrument argument (cf. 13a, 14a and $15 a)$, which turns up as subject in (13b), (14b) and (15b). Taking into account the first subevent in the templates codified by sound and speak verbs, if (w) is chosen as Actor (the unexceptional situation if (w) is lexically saturated), then (voice) and (words), respectively, as non-macrorole arguments will take dative or genitive case.

On the other hand, when $(w)$ is not syntactically realised (cf. the alternations in $b$.), the following candidates to function as actor will be (v) and (words), respectively. The constructional templates in (b.) will be modulated by the lexical mapping rule "suppression of variables", which regulates the procedure for the suppression of the variables contained in the corresponding lexical representations.

\subsection{Cognate object construction}

In RRG, activity verbs are considered intransitive, since their second argument cannot be assigned the macrorole undergoer due to its non-referential inherent nature (Van Valin and LaPolla, 1997: 122-125; 147-154). Accordingly, a cognate object is considered non- 
referential, since it "expresses an intrinsic facet of the meaning of the verb and does not refer specifically to any participants in an event denoted by the verb" (1997: 123):

(16) a. Sarah sang.

b. Sarah sang a song. (Levin, 1993: 95)

In the cognate object construction codified by sound emission verbs in Old English, the variable $(\mathrm{w})$ takes macrorole actor and nominative case and the second argument (sound) in genitive will be treated as a non-macrorole core argument. As the Lexical Template Modelling Process stipulates, the corresponding construction-based template below designating a causative activity and the lexical template codified by sound emission verbs meet the lexical mapping rule "full matching":

$\left[\left[\right.\right.$ do $^{\prime}$ (w, [use' (w, v/voice)] CAUSE [produce' (w, sound').in.a.loud.manner.(ä) (w, sound)]l

(17) Herewopa (sound: genitive) moest aðe cyrmdon (w: elliptical-actor) (B\&T) Cries of an army-most-hateful-cried out (they).

6.6. Unspecified object construction

With regard to the unspecified object alternation, Levin (1993: 33) posits that "despite the lack of overt direct object in the intransitive variant, the verb in this variant is understood to have as object something that qualifies as a typical object of the verb":

(18) a. Mike ate the cake.

b. Mike ate. (? Mike ate a meal or something one typically eats.)

Therefore, the constructional template below corresponding to speak verbs and containing a causative activity will be motivated by the lexical mapping rule "suppression of variables", which regulates the procedure for the suppression of the variable (y) contained in the subclass-based lexical representation above:

\section{[do' (w, [use' (w, voice/words)] CAUSE [do' (w,} [express.(á).to.( $\beta)$.in.language. $\left.\left.\left.(\gamma)^{\prime}(w, \varnothing)\right]\right)\right]$, where $\varnothing=\beta$

In this regard, the variable (w) takes macrorole actor and nominative case:

(19) he (w: nominative-actor) ar gespraec (DOEC: Beo A4.1)

He-before-talked. 


\subsection{Stative construction}

The last relevant construction shown by smell emission verbs is the stative construction. As can be observed, the constructional template below and the subclass-based lexical template codified by smell emission predicates meet the lexical mapping rule "full matching":

[have.smell', [be' (smell, [(un)pleasant'])] (z)]

Regarding the so-called stimulus subject perception verbs in Present-day English, Levin (1993: 188) points out the fact that these predicates "do not take the perceiver as their subject. Rather, these verbs take the stimulus as their subject and express the perceiver in a to prepositional phrase. In addition, these verbs take an adjective phrase complement predicated of the stimulus":

(20) That pea soup tasted delicious to me.

However, in opposition to Present-day English, Old English smell emission verbs participating in the stative construction do not express lexically the perceiver. In this constructional template there will be only a macrorole undergoer corresponding to the emitter of a pleasant (21a) or unpleasant (21b) smell, that is, (z). This variable will take macrorole undergoer and nominative case since the state of affairs in this constructional template denotes a stative LS (González, forthcoming):

(21) a. se lichoma ( $\mathrm{z}$ : nominative-undergoer) stanc ond paet heafod ( $\mathrm{z}$ : nominativeundergoer) swa swote swa rosan blostma ond lilian (HSK: Comartyr $<\mathrm{R}$ $2373>$ )

The-body-smelt-and-the-head-as-sweaty as-roses-and-lilies.

[have.smell', [be' (smell, [pleasant'])] (z)]

b. ond ic fulre eom ponne pis fen swearte pat her yfle adelan (z: nominativeundergoer) stinced (HSK: Coriddle <R 27>)

And-I-more unclean-am-than-this-dirt-dark-that-here-evil-mud-smells.

[have.smell', [be' (smell, [unpleasant $\left.\left.\left.\left.{ }^{\prime}\right]\right)\right](\mathrm{z})\right]$

As a concluding remark, the verb subclasses described above have allowed us to exemplify seven semantic constructions with their corresponding morpho-syntactic configuration: transitive, resultative, reaction object, instrument subject, cognate object, unspecified object, and finally the stative construction. Taking into account the semantic 
nature of the verbal predicates under study, they will participate in the following constructions:

a) remember verbs:

These cognitive predicates illustrate macrorole-transitive verbs taking both actor and undergoer macroroles and designating an accomplishment. Therefore, they can be found in the transitive and the resultative constructions.

b) sound emission verbs:

As activity predicates they are considered macrorole-intransitive verbs with a single actor macrorole as in the reaction object, the instrument subject and the cognate object constructions.

c) speak verbs:

They are primarily considered macrorole-intransitive activity verbs taking only an actor macrorole as both the instrument subject and the unspecified object constructions show. However, when involved in the resultative construction, speak verbs will designate a causative accomplishment. The semantic feature differentiating their Aktionsart is the telicity of the latter, which will activate a causative transitive structure, in opposition to the intransitive use of activity verbs.

d) smell emission verbs:

They exemplify perception verbs denoting a state. In doing so, they are regarded as macrorole-intransitive verbs taking, therefore, as their only macrorole an undergoer (cf. the stative construction). However, when these verbs take part in the resultative construction, they behave as macrorole-transitive causative states showing the actor and undergoer macroroles.

\section{Conclusions}

This paper has described the interaction between the semantic structure of the set of remember, smell emission, sound emission and speak verbs in Old English and their syntactic behaviour, together with the morphological marking of the constituents in the sentences where they appear. Our proposal of a subclass-based lexical template for each verb subclass, together with a set of linking mechanisms between these templates and the constructional templates and morpho-syntactic patterning exhibited by its members, offers a way to capture the interrelation of the semantic and syntactic structure of these verbal predicates.

As a result, this paper has provided a catalogue of the syntactico-semantic constructions exhibited by the verb classes under study, to our understanding highly representative of the constructions codified by the Old English verbal lexicon. 
Nevertheless, the analysis of specific subclass-based constructions will need further investigation.

\section{Notes}

1. This paper is part of the research projects EX2003-0118 and BFF2002-00659, funded by the State University Office with Social European Funds, and the Spanish Ministry of Science and Technology, respectively.

2. According to Van Valin and LaPolla (1997: 665), genitive can replace dative in order to mark a non-macorole argument since "dative is the default case for non-macrorole direct core arguments, and as a default case it must be overridden with certain verbs".

\section{Works Cited}

Allen, Cynthia L. (1995): Case Marking and Reanalysis: Grammatical Relations from Old to Early Modern English. Oxford and New York: Clarendon Press.

Bosworth, Joseph and T. Northcote Toller (1973): An Anglo-Saxon Dictionary. Oxford: Oxford University Press.

Cortés, Francisco J. and Marta González (2004): "The interrelation of semantic structure and syntactic patterning in the Old English verbs of 'sound emission'". Paper presented at the XXVIII Aedean International Conference. University of Valencia.

Cortés, Francisco J. and Ricardo Mairal (2002): "A Preliminary Design for a Syntactic Dictionary of Old English on Semantic Principles". In J. Diaz, ed., A Changing World of Words. Amsterdam: Rodopi, 3-46.

Cortés, Francisco J. and Dolores Torres (2003, forthcoming): "Old English Verbs-of-Running: Linking Semantic Representation and Morphosyntactic Structure". Folia Linguistica Historica XXIV.

Denison, David (1993): English Historical Syntax: Verbal Constructions. London and New York: Clarendon Press.

Faber, Pamela and Ricardo Mairal (1999): Constructing a Lexicon of English Verbs. Berlin: Mouton de Gruyter.

Fischer Olga, Ans van Kemenade, Willem Koopman and Wim van der Wurff (2000): The Syntax of Early English. Cambridge: CUP.

González, Marta (2004): "Argument-marking and argument-adjunct prepositions within the lexical domain of speech in Old English". Atlantis 26, 1: 11-21.

. (forthcoming): "The Old English Verbs of Smell Perception and Emission: Analysis of the Interface of their Semantic and Syntactic Representation". Selim 12.

Hall, John Richard Clark (1996): A Concise Anglo-Saxon Dictionary. Toronto: University of Toronto Press.

Healey, Antonette di Paolo (ed.): The Dictionary of Old English Corpus. Available on the Internet: http://www.hti.umich.edu/english/oec.

Kailuweit, Rolf (2004): "La Gramática de Papeles y Referencia y las lenguas románicas". Course lectured at La Laguna University. 
Levin, Beth (1993): English Verb Classes and Alternations. Chicago and London: The University of Chicago Press.

Mairal, Ricardo and Francisco J. Cortés (forthcoming): "Rethinking Lexical Represen-tations in Role and Reference Grammar". In D. Kastovsky, ed., The English Lexicon: Structure and Genesis. Berlin: Mouton de Gruyter.

Mairal, Ricardo and Pamela Faber (2002): "Functional Grammar and Lexical Templates". In R. Mairal and M. J. Pérez, eds., New Perspectives on Argument Structure in Functional Grammar. Berlin: Mouton de Gruyter, 39-94.

McLaughlin, John C. (1983): Old English Syntax: A Handbook. Tübingen: Niemeyer.

Mitchell Bruce C. (1985): Old English Syntax. Oxford: Oxford University Press.

Rissanen, Matti and Ossi Thalainen (1991): The Helsinki Corpus of English Texts: Diachronic and Dialectal. Helsinki: University of Helsinki.

Roberts, Jane and Christian Kay (1995): A Thesaurus of Old English. London: King's College London Medieval Studies.

Toller T. Northcote and Alistar Campbell (1972): An Anglo-Saxon Dictionary. Supplement. Oxford: Oxford University Press.

Van Valin, Robert D. (2004): "Lexical Representation, Co-composition, and Linking Syntax and Semantics". In http://wings.buffalo.edu/linguistics/rrg.

Van Valin, Robert D. and Randy LaPolla (1997): Syntax: Structure, Meaning and Function. Cambridge: Cambridge University Press.

Van Valin, Robert D. and David P. Wilkins (1993): "Predicting Syntactic Structure from Semantic Representation: Remember in English and its Equivalents in Mparntwe Arrernte." In R. D. Van Valin, ed., Advances in Role and Reference Grammar. Amsterdam: Benjamins, 499-534. 